\title{
Crosslinked poly(ether ether ketone): cost-effective proton exchange membranes for fuel cell application
}

\author{
SWATI AWASTHI, VAISHNAV KIRAN and BHARTI GAUR*D \\ Department of Chemistry, National Institute of Technology Hamirpur, Hamirpur 177005, India \\ *Author for correspondence (bhartigaur@gmail.com)
}

MS received 19 October 2016; accepted 11 June 2017; published online 2 February 2018

\begin{abstract}
Sulphonated poly(ether ether ketone) copolymers bearing pendant carboxylic acid (SPEEK-C) have been synthesized via nucleophilic condensation reaction of 4,4'-difluorobenzophenone, sulphonated 4,4'-difluorobenzophenone and 3,5-dihydroxy benzoic acid. The structure of the sulphonated copolymer was identified from FT-IR and ${ }^{1} \mathrm{H}-\mathrm{NMR}$ spectrum. The pendant carboxylic groups of SPEEK-C were further crosslinked with poly(vinyl alcohol) (PVA) to fabricate the crosslinked (SPEEK/PVA) membranes. The performance of the membranes was evaluated in terms of water uptake, proton conductivity and oxidative stability. The thermal stabilities of the membranes were determined by thermogravimetric analysis and differential scanning calorimetry techniques, whereas the morphological analysis was performed by atomic force microscopy.
\end{abstract}

Keywords. Random copolymers; sulphonation; crosslinking; morphology; thermal stability.

\section{Introduction}

In today's scenario, fuel cell technology is a long-term solution of ever-growing demand for clear and reliable alternative energy sources. The main emphasis in the present time is on the development of fuel cells, due to its high energy conversion efficiency, quick start-up, portability and minimal pollutant release. Among the various types of developed fuel cells, proton exchange membrane fuel cells (PEMFCs) are the most promising power resources and are currently being evolved for a wide scope of applications such as those in transportation and portable electronic devices and as a primary energy source in remote regions [1-3].

As a key component of PEMFCs, proton exchange membranes (PEMs) have been extensively investigated in recent years. The PEM is a proton-conducting polymer material, which acts as a fuel gas barrier between the two respective electrodes of PEMFCs. Perfluorosulphonic acid (PFSA) membranes or DuPont's Nafion ${ }^{\circledR}$ membranes are the most commonly used commercially available membranes in PEMFCs owing to their excellent proton conductivity and long-term stability at moderate temperature. However, these membranes are also associated with some drawbacks such as their high cost, poor proton conductivity and high fuel permeability at temperature above $80^{\circ} \mathrm{C}$, which stimulated the development of other hydrocarbon-based polymer membranes $[4,5]$. These hydrocarbon-based aromatic polymer membranes, including poly(ether ether ketone) [PEEK], poly(ether sulphone) [PES], poly(ether nitrile) [PEN], polybenzimidazole [PBI], poly(phthalazinone ether) [PPPE] and poly(aryl amide), have been widely studied in the recent years [6-10]. Out of these, the PEEK are an important class of high-performance thermoplastics that possess high thermal stability and mechanical integrity along with low economical factor as compared with the Nafion membrane [11]. The pendant carboxylic or sulphonic acid groups present on the main backbone of the polymer chain enhance the proton conductivity of the membrane [12-14]. These pendant groups have also been utilized further for crosslinking to improve the dimensional stability and various fuel-cell-related properties of the pristine membrane $[15,16]$. Studies of poly(vinyl alcohol) [PVA]-based membranes have shown that they possess excellent film-forming properties, besides showing high chemical resistance and thermo-stability [17]. Therefore, in this work, PVA, a non-halogenated aliphatic polymer, has been selected for crosslinking with the pendant carboxylic acid groups of sulphonated PEEK copolymers bearing pendant carboxylic acid (SPEEK-C). Many researchers have reported the crosslinking of PVA with SPEEK. However, to the best of our knowledge, there is no report of incorporating the inexpensive 3,5-dihydroxy benzoic acid (DHBA) bearing pendant $\mathrm{COOH}$ group for the synthesis of sulphonated PEEK (SPEEK-C) copolymer and further utilizing this pendant carboxylic acid group in the crosslinking of the copolymer with PVA.

In the present work, the 4,4'-difluorodiphenylketone (DFDPK) monomer was firstly sulphonated and then the direct copolymerization of DHBA, sulphonated 4,4'difluorodiphenylketone (SDFDPK) and DFDPK was carried out for the synthesis of SPEEK-C. The pendant $-\mathrm{COOH}$ moiety of SPEEK-C was further crosslinked with the hydroxyl 


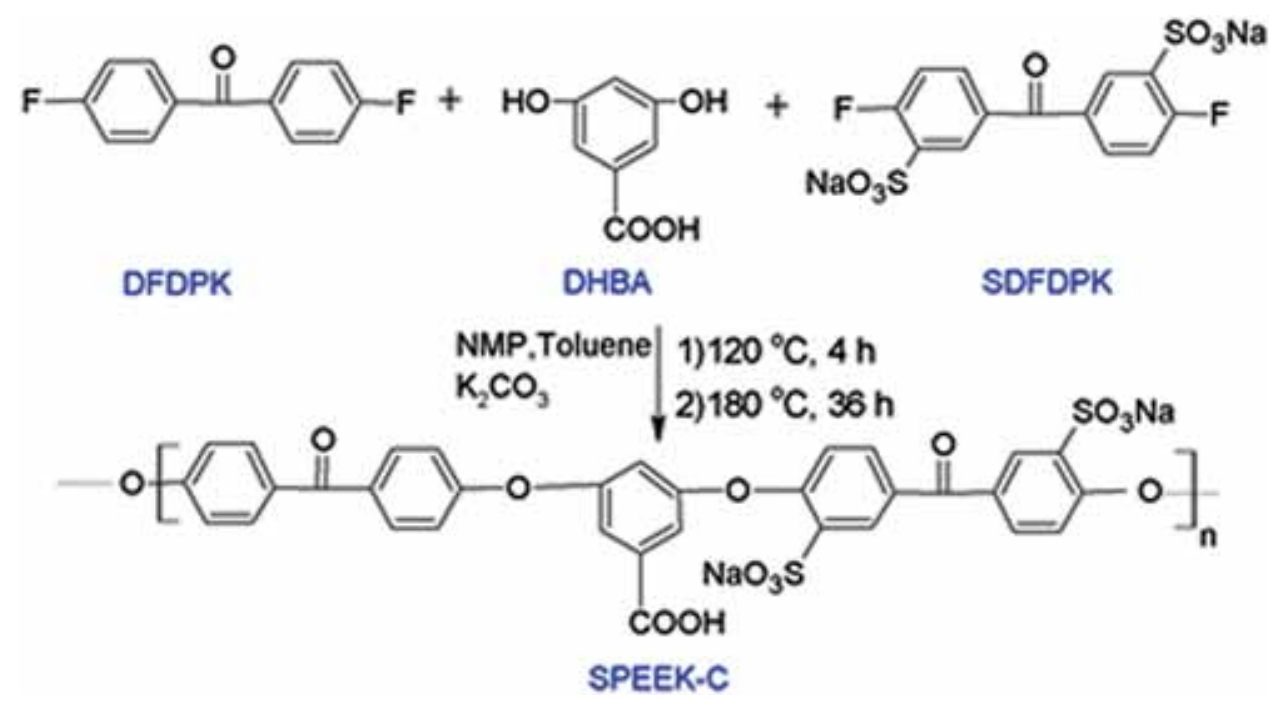

Figure 1. Synthesis of SPEEK-C copolymer.

group of PVA to form novel SPEEK/PVA crosslinked membranes.

The main aim of this study was to produce thermally and oxidatively stable, flexible membranes by crosslinking the SPEEK-C copolymer and at the same time maintaining the required proton conductivity. The effect of crosslinking on other fuel-cell-related properties of membranes by varying the content of PVA was also studied in detail and the results were compared with that of the pristine membrane.

\section{Material and methods}

\subsection{Materials}

DFDPK and DHBA were purchased from Sigma Aldrich (Germany) and fuming sulphuric acid (20\%) was received from Spectrochem (Mumbai, India); PVA (molecular weight $1,15,000 \mathrm{~g} \mathrm{~mol}^{-1}$ ) and $\mathrm{K}_{2} \mathrm{CO}_{3}$ were obtained from Loba Chemie (Mumbai, India); the other solvents N-methyl-2pyrrolidone (NMP), toluene and isopropyl alcohol were received from Alfa Aesar Chemicals (England) and were used as received.

\subsection{Synthesis of SDFDPK}

The SDFDPK monomer was prepared by adding DFDPK $(15 \mathrm{mmol})$ and $20 \%$ fuming sulphuric acid $(12 \mathrm{ml})$ into a $100-\mathrm{ml}$ three-necked round bottom flask equipped with an overhead mechanical stirrer and a condenser. The temperature of the reaction mixture was slowly raised to $110^{\circ} \mathrm{C}$ and stirred at that temperature for $6 \mathrm{~h}$. After cooling the reaction mixture to the room temperature, it was poured into $200 \mathrm{ml}$ of ice water, followed by neutralization with $2 \mathrm{M} \mathrm{NaOH}$ to obtain $\mathrm{pH}$ value of 8 . The product was precipitated out in the form of white solids by adding excess of $\mathrm{NaCl}$ salt to the solution. The white solid precipitates were filtered and dried overnight. Recrystallization of the obtained precipitates was carried out from a mixture of methanol/water (9:1).

\subsection{Synthesis of SPEEK-C}

SPEEK-C was prepared by the copolymerization condensation reaction of DFDPK $(10 \mathrm{mmol})$, SDFDPK $(10 \mathrm{mmol})$ and DHBA (20 mmol) via nucleophilic aromatic substitution reaction in the presence of $\mathrm{K}_{2} \mathrm{CO}_{3}(23 \mathrm{mmol})$, NMP $(30 \mathrm{ml})$ and toluene $(15 \mathrm{ml})$. The reaction was carried out in a 250 $\mathrm{ml}$ three-necked round bottom flask fitted with a mechanical stirrer and Dean-Stark trap. Firstly, the reaction mixture was refluxed at $120^{\circ} \mathrm{C}$ for $4 \mathrm{~h}$ in order to remove the generated water via distillation process. The temperature of the reaction mixture was slowly increased to $180^{\circ} \mathrm{C}$ and maintained for the next $36 \mathrm{~h}$ until the reaction mixture became very viscous. The reaction mixture was cooled, diluted with $5 \mathrm{ml}$ of NMP and was further precipitated out in isopropyl alcohol. The precipitates were filtered and dried at $70^{\circ} \mathrm{C}$ in a hot air oven. The reaction scheme is shown in figure 1.

\subsection{Membrane preparation}

SPEEK-C membrane was prepared by solution casting method. The dried SPEEK-C copolymer was completely dissolved in NMP solution $(10 \% \mathrm{w} / \mathrm{v})$, and further cast onto a clean flat glass plate. The crosslinked SPEEK/PVA-XX (where $\mathrm{XX}$, refers to the weight percentage of PVA to the SPEEK-C) membranes were fabricated by adding the measured amount of PVA to the SPEEK-C dissolved in NMP $(10 \% \mathrm{w} / \mathrm{v})$. The solution was stirred for $12 \mathrm{~h}$ at $70^{\circ} \mathrm{C}$, and then cast onto the clean glass plate at $60^{\circ} \mathrm{C}$ for another $24 \mathrm{~h}$ followed by heating at $120^{\circ} \mathrm{C}$ for the next $12 \mathrm{~h}$. The pristine 

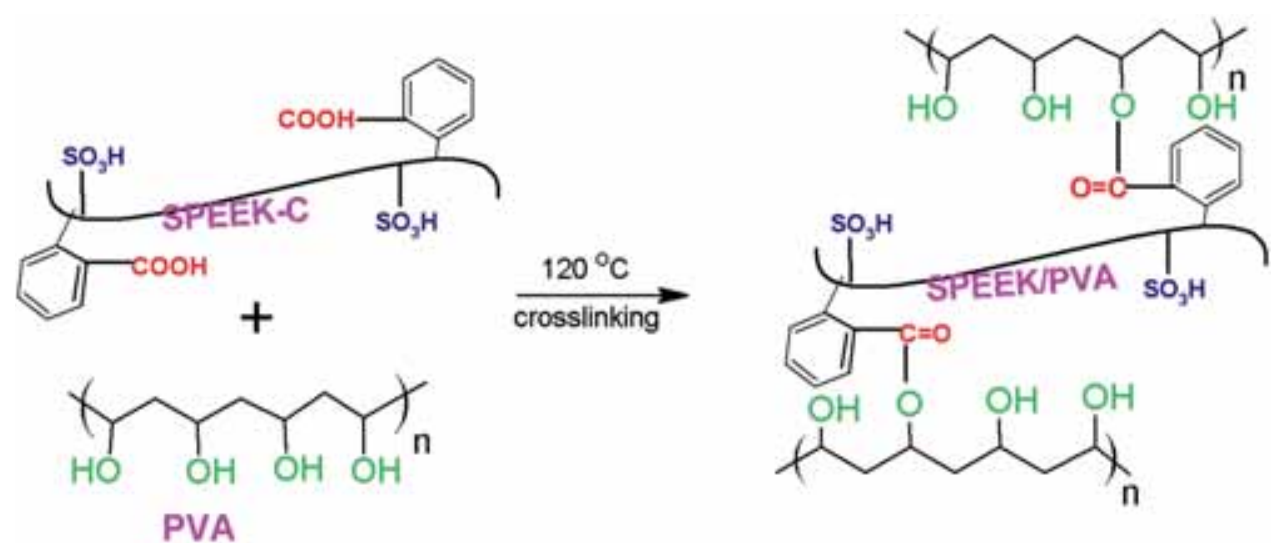

Figure 2. Schematic representation of crosslinking of SPEEK-C with PVA.

SPEEK-C and the crosslinked membranes SPEEK/PVA-XX were peeled off from the glass plate and rinsed several times with $1 \mathrm{M} \mathrm{HCl}$ solution. A schematic representation of the crosslinked membrane is shown in figure 2 .

\subsection{Copolymer characterization}

FT-IR spectra of the samples were recorded using a Perkin Elmer 1600 FT-IR spectrophotometer in the range of 4000$400 \mathrm{~cm}^{-1}$ on KBR pellets. ${ }^{1} \mathrm{H}-\mathrm{NMR}$ spectra were recorded on a BRUKER AVANCE II 400 NMR spectrometer using deuterated DMSO-d6 as a solvent and TMS as the internal standard.

\subsection{Membrane characterization}

2.6a Ion exchange capacity (IEC): Ion exchange capacity (IEC) of the membranes was determined by titration method. A weighed sample membrane $(0.2 \mathrm{~g})$ in proton form was immersed in $30 \mathrm{ml}$ of $2 \mathrm{M} \mathrm{NaCl}$ solution at room temperature for $48 \mathrm{~h}$ in order to exchange the $\mathrm{H}^{+}$ions with $\mathrm{Na}^{+}$ ions. The amount of $\mathrm{H}^{+}$released from the membrane samples was determined by titrating with $0.01 \mathrm{M} \mathrm{NaOH}$ solution using phenolphthalein as an indicator:

$$
\text { IEC }=\frac{\text { Consumed } \mathrm{NaOH}(\mathrm{ml}) \times \text { molarity of } \mathrm{NaOH}}{\text { Weight of dry membrane }(\mathrm{g})}\left(\text { meq g }^{-1}\right) \text {. }
$$

2.6b Water uptake and swelling ratio: The water uptake and swelling ratio of the sample membranes were determined by measuring the difference in weight and length between the fully hydrated membrane and the dry membrane, respectively. All the sample membranes were cut into $2 \mathrm{~cm} \times 2 \mathrm{~cm}$ pieces and then weighed. After that, the samples were immersed into $20 \mathrm{ml}$ of distilled water for $24 \mathrm{~h}$. The wet membranes were wiped off with a filter paper and immediately weighed. For each testing, at least three measurements were made and the average value was considered. Water uptake of the membranes was calculated as follows:

$$
\text { Water uptake }(\%)=\frac{W_{\mathrm{w}}-W_{\mathrm{d}}}{W_{\mathrm{d}}} \times 100,
$$

where $W_{\mathrm{w}}$ and $W_{\mathrm{d}}$ are the weights of wet and dry membranes, respectively.

The water swelling ratio of the membranes was calculated from the following equation:

$$
\text { Swelling ratio }(\%)=\frac{l_{\mathrm{w}}-l_{\mathrm{d}}}{l_{\mathrm{d}}} \times 100,
$$

where $l_{\mathrm{w}}$ and $l_{\mathrm{d}}$ are the lengths of wet and dry membranes, respectively.

2.6c Proton conductivity: The proton conductivity of the membrane was measured by four-point probe technique as reported in our previous work $[17,18]$. Firstly, the membranes $(2 \mathrm{~cm} \times 2 \mathrm{~cm})$ were immersed in distilled water for $24 \mathrm{~h}$ at room temperature. Then, the piece of membrane was wiped off and mounted on the cell attached to a Keithley 6221 sourcemeter and Keithley 2182A nanovoltmeter. Alternating current $I$ in the range of $0.1-1.0 \mathrm{~mA}$ was applied to the cell and the corresponding voltage was noted. By voltage-current $(V-I)$ plot, the resistance was obtained as follows:

$$
\text { Resistivity } \begin{aligned}
\rho= & \frac{V}{I} \times \text { thickness of the membrane } \\
& \times \frac{\pi}{\ln 2} \Omega \mathrm{cm},
\end{aligned}
$$

Conductivity $\sigma=\frac{1}{\rho} \mathrm{S} \mathrm{cm}^{-1}$.

2.6d Oxidative stability: For oxidative stability, a small piece of membrane sample $(0.2 \mathrm{~g})$ was immersed into Fenton's reagent $\left(6 \% \mathrm{H}_{2} \mathrm{O}_{2}\right.$ containing 3 ppm $\left.\mathrm{FeSO}_{4}\right)$ solution at $80^{\circ} \mathrm{C}$. The time when the membrane started to become brittle $\left(T_{1}\right)$ and the time when it dissolved completely $\left(T_{2}\right)$ in the Fenton's reagent were noted. 
2.6e Methanol permeability: Methanol permeability was determined using a diffusion cell consisting of two compartments $\mathrm{A}$ and $\mathrm{B}$, which were partitioned by the membrane sample. Methanol solution (1 M) was poured in one compartment (A) of the diffusion cell and in the other compartment (B), distilled water was added. Both the compartments were magnetically stirred continuously during the permeation experiments to ensure uniformity. The concentration of water and methanol in the compartments A and B, respectively, was measured using a T80 UV/VIS spectrometer. The methanol permeability $\left(D_{\mathrm{K}}\right)$ is evaluated using equation (6):

$$
C_{\mathrm{B}}=\frac{A\left(D_{\mathrm{K}}\right) C_{\mathrm{A}}}{V_{\mathrm{B}} L}\left(t-t_{0}\right) .
$$

$C_{\mathrm{A}}$ and $C_{\mathrm{B}}$ are the concentrations of the methanol and $V_{\mathrm{A}}$ and $V_{\mathrm{B}}$ are the volumes of liquids in compartments $\mathrm{A}$ and $\mathrm{B}$, respectively, $t$ and $t_{0}$ are the initial and final diffusion time, $A$ and $L$ are the area and thickness of the membranes.

2.6f Selectivity ratio: Proton conductivity as a function of methanol permeability was also calculated. The selectivity ratio of the membranes was calculated from proton conductivity and methanol permeability ratio, i.e. $\sigma / D_{\mathrm{K}}$.

2.6g Thermal properties: Thermal degradation and the glass transition temperature of the membranes were examined using a thermogravimetric/differential thermal analyzer EXSTAR TG/DTA 6300. For thermogravimetric analysis (TGA), a sample of size $10 \pm 1 \mathrm{mg}$ was heated from 25 to $900^{\circ} \mathrm{C}$ in $\mathrm{N}_{2}$ atmosphere $\left(200 \mathrm{ml} \mathrm{min}^{-1}\right)$ at a heating rate of $10^{\circ} \mathrm{C} \mathrm{min}{ }^{-1}$.

The glass transition temperature of the membranes was measured by preheating the sample in $\mathrm{N}_{2}$ atmosphere $(200 \mathrm{ml}$ $\mathrm{min}^{-1}$ ) from room temperature to $110^{\circ} \mathrm{C}$ at a scanning rate of $10^{\circ} \mathrm{C} \mathrm{min}^{-1}$ to remove the moisture, then cooled to $50^{\circ} \mathrm{C}$ and reheated from 50 to $300^{\circ} \mathrm{C}$ at a heating rate of $10^{\circ} \mathrm{C} \mathrm{min}^{-1}$.

2.6h Morphological characterization: The surface morphology of the membranes was studied on a Dimension Icon (Bruker) atomic force microscopy (AFM) instrument under tapping mode at room temperature. The oscillation frequency was set to approximately $320 \mathrm{kHz}$ with a TESPA cantilever, which had a force constant of about $42 \mathrm{~N} \mathrm{~m}^{-1}$. Threedimensional height images of all the samples were recorded at the resonance frequency of the cantilever with a scan rate of $0.7 \mathrm{~Hz}$.

\section{Results and discussion}

\subsection{Synthesis of SDFDPK monomer}

The sulphonation of DFDPK by fuming sulphuric acid is an electrophilic substitution reaction. Figure 3 a presents the ${ }^{1} \mathrm{H}-\mathrm{NMR}$ spectrum of sulphonated benzophenone SDFDPK. The proton adjacent to the sulphonate group is more deshielded and appears at $8.4 \mathrm{ppm}$, whereas the other two aromatic protons appear at 8.2 and $7.7 \mathrm{ppm}$. The degree of sulphonation (DS) of the sulphonated monomer SDFDPK was evaluated by taking the ratio of the integrated protons (a) adjacent to the sulphonated group to the other known aromatic protons (b and c), as in the following equation [19]:

$$
\begin{aligned}
& \overline{\text { No. of protons with different electron density }} \\
& =\frac{\text { Integral of proton } a}{\text { Sum of integral of proton } b \text { and } c}, \\
& \text { DS }(\%)=n \times 100, \text { where } 0<n<1
\end{aligned}
$$

From equations (7) and (8), by substituting the integral values, $n$ has been calculated as 0.7 , and therefore $\mathrm{DS}=70 \%$.

\subsection{Synthesis of SPEEK-C copolymer}

The FT-IR spectra of pristine membrane and its crosslinked counterparts are shown in figure $3 \mathrm{~b}$. The characteristic peaks at 1647,1115 and $1016 \mathrm{~cm}^{-1}$ correspond to the stretching vibrations of aromatic $\mathrm{C}=\mathrm{O}$ group and asymmetric, symmetric stretching vibration of $\mathrm{O}=\mathrm{S}=\mathrm{O}$ group of sulphonic group, respectively. The absorption peak at $\sim 3438 \mathrm{~cm}^{-1}$ can be assigned to the $\mathrm{O}-\mathrm{H}$ stretching vibration of $-\mathrm{COOH}$ and $-\mathrm{SO}_{3} \mathrm{H}$ moiety of SPEEK-C, which shifted to a higher wavenumber $\sim 3610 \mathrm{~cm}^{-1}$ for crosslinked membranes. The crosslinked membranes SPEEK/PVA-XX exhibit the characteristic peak at $1770 \mathrm{~cm}^{-1}$, which confirms the formation of the ester bond between pendants - $\mathrm{COOH}$ group and - $\mathrm{OH}$ of PVA. As the percentage of PVA increases, the intensity of the characteristic peak at $1770 \mathrm{~cm}^{-1}$ also increases.

The ${ }^{1} \mathrm{H}-\mathrm{NMR}$ spectra of SPEEK-C copolymer is shown in figure 4. The distinctive protons at C-1, C-6 and C-7 appeared in the more deshielded area $(\delta 7.7-7.83 \mathrm{ppm})$ due to the strong electron withdrawing effect of adjacent sulphonic group and carboxylic group. The other aromatic protons showed signals from 6.92 to $7.53 \mathrm{ppm}$.

\subsection{Water uptake and swelling ratio}

The water uptake and swelling ratio of PEM have large effect on the performance of the fuel cell. The water molecules act as carriers involved in proton conduction with proton hopping from one water molecule to the next by the formation and breaking of $\mathrm{O}-\mathrm{H}$ bonds (Grotthuss mechanism) and matrix transport in which proton does not move as $\mathrm{H}^{+}$through the water medium but as $\mathrm{H}_{3} \mathrm{O}^{+}, \mathrm{H}_{5} \mathrm{O}_{2}^{+}$and $\mathrm{H}_{9} \mathrm{O}_{4}^{+}$ion, which is bonded to the vehicle such as $\mathrm{H}_{2} \mathrm{O}$ [20]. More the membrane gets hydrated, better the transportation of protons followed by an enhancement in IEC and proton conductivity of the membrane. However, with very high water uptake the membrane swells or becomes water soluble and loses its dimensional stability. The water uptake of the SPEEK-C and its crosslinked membranes is shown in figure 5. The pristine SPEEK-C 
(a)
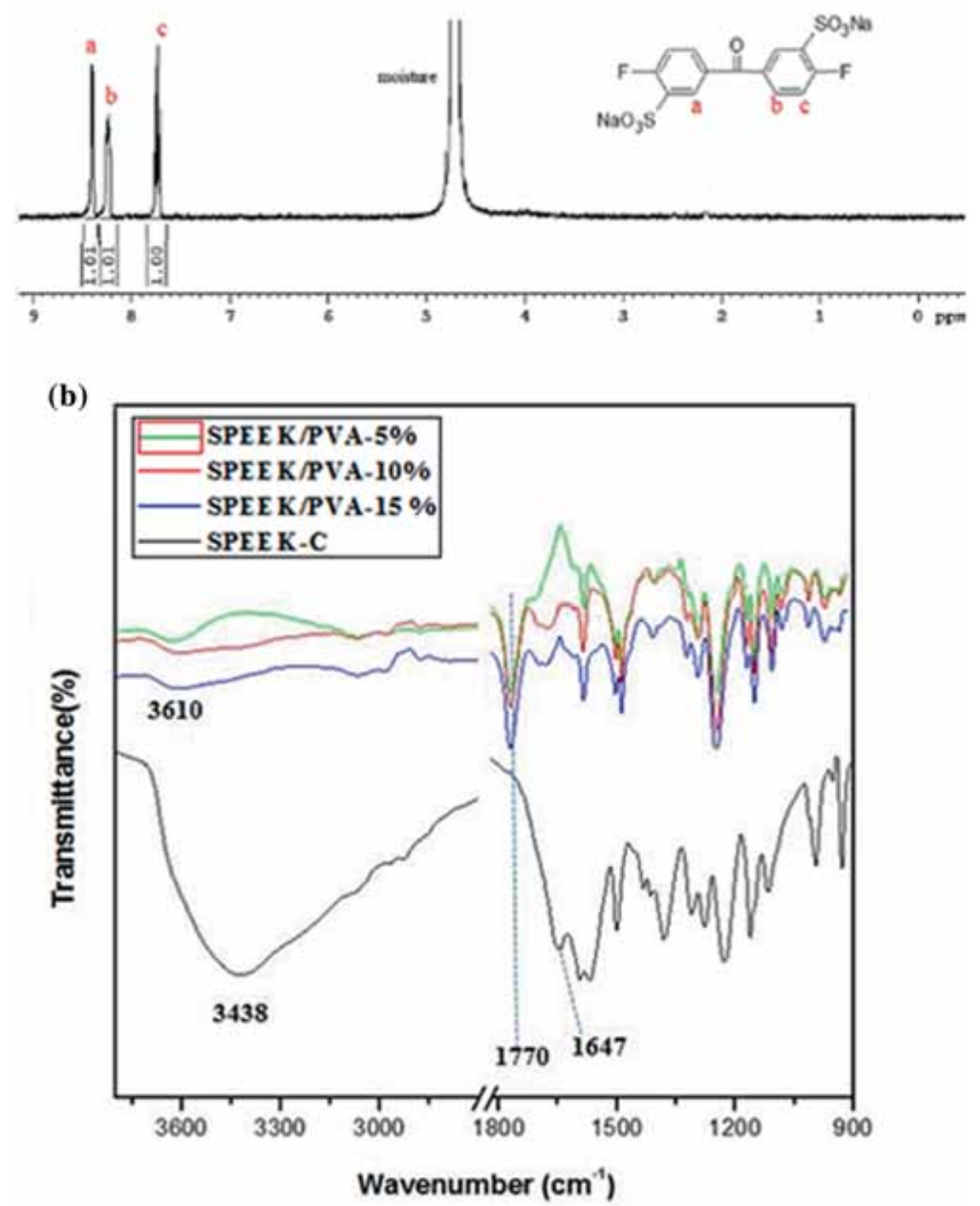

Figure 3. (a) ${ }^{1} \mathrm{H}-\mathrm{NMR}$ of SDFDPK and (b) FT-IR spectra of SPEEK-C and its crosslinked membranes.

membrane shows higher water uptake, which decreases in case of crosslinked SPEEK/PVA-5\% and SPEEK/PVA-10\% membranes. With the addition of PVA, the extent of crosslinking increases, which decreases the number of $-\mathrm{OH}$ moieties of carboxylic group and thus these membranes show a reduction in the water uptake. However, for SPEEK/PVA-15\% membrane, increment in the water uptake was attributed to the off-stoichiometric ratio of PVA crosslinker in SPEEK-C. The swelling ratio curve also shows a similar behaviour as shown by the water uptake curve (figure 5).

\subsection{IEC and proton conductivity}

IEC is defined as the number of milliequivalents of exchangeable acid protons per gram of the dry polymer, whereas the proton conductivity is defined as the capability of the transportation of protons, which determines the power generation of a fuel cell. The IEC and proton conductivity of the membranes are listed in table 1. Although the crosslinked membranes had lower water uptake than that of pristine membranes, the former membranes displayed a very 

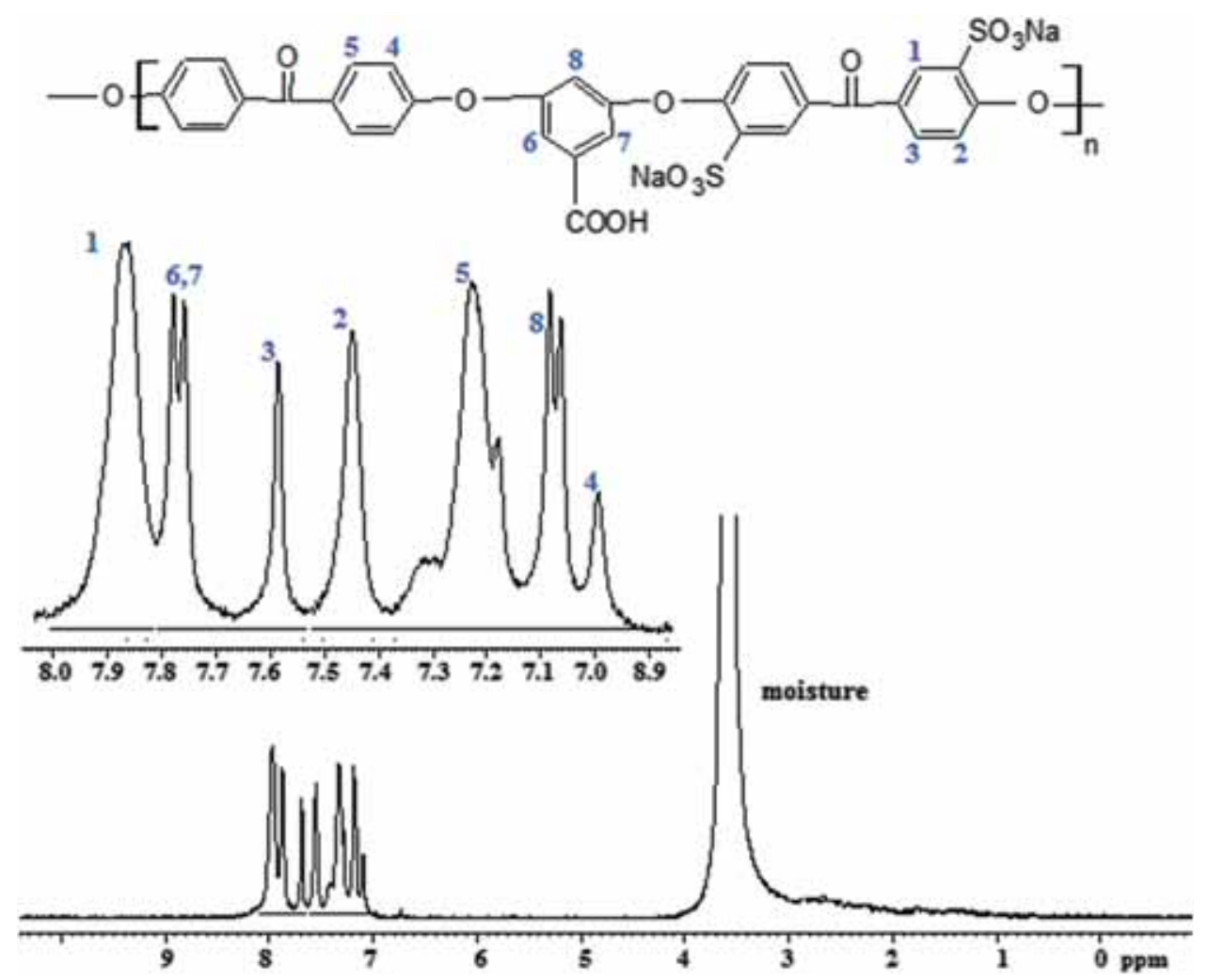

Figure 4. ${ }^{1} \mathrm{H}-\mathrm{NMR}$ of SPEEK-C copolymer.

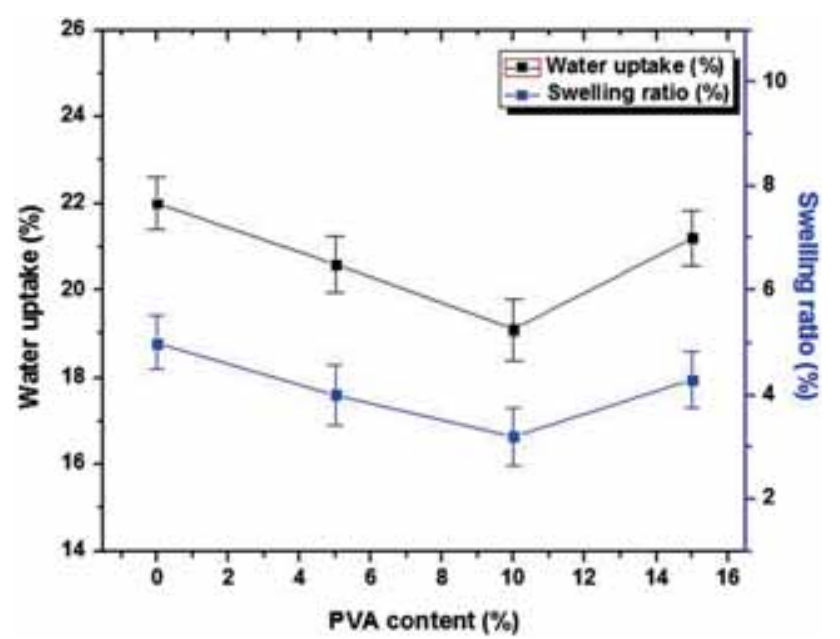

Figure 5. Water uptake and swelling ratio of SPEEK/PVA-XX membranes with increase in PVA content $(0,5,10$ and $15 \mathrm{wt} \%)$.

slight decrease in IEC and proton conductivity as compared with the latter ones. This is because during the crosslinking reaction, though the number of $-\mathrm{COOH}$ acid groups gets reduced, the number of sulphonic groups still remains intact in the polymeric chain and therefore accounts for the comparable proton conductivity of the crosslinked membranes to that of pristine membrane SPEEK-C.

\subsection{Oxidative stability}

For the practical fuel cell application, the PEM must have good oxidative stability. The PEMs often suffer from degradation due to the attack from hydroxyl $\left(\mathrm{HO}^{\bullet}\right)$ and hydroperoxyl $\left(\mathrm{HOO}^{\circ}\right)$ radicals. These radicals are generated by the reaction of $\mathrm{H}_{2}$ and $\mathrm{O}_{2}$ at the anode, and $\mathrm{H}_{2} \mathrm{O}_{2}$ reacts with the trace metal ions to form the radicals at the cathode [11]. In the Fenton reagent $\left(\mathrm{H}_{2} \mathrm{O}_{2}\right.$ and $\left.\mathrm{Fe}^{2+}\right)$, the decomposition of $\mathrm{H}_{2} \mathrm{O}_{2}$ in the presence of catalysis $\mathrm{Fe}^{2+}$ could generate the strong oxidizers such as $\mathrm{HO}^{\circ}, \mathrm{HOO}^{\circ}, \mathrm{Fe}^{3+}$ and $\mathrm{O}_{2}$. Thus, the real time conditions during the working of a fuel cell can be simulated using the Fenton test in order to determine the oxidative stability of the membrane samples. These radicals are likely to attack the phenylene carbons ortho to the ether bonds due to their high electron density. However, the presence of strong electron-withdrawing ketone and pendant carboxylic acid groups in the backbone of polymer chain deactivated the ortho carbons by reducing the electron density, which led to less oxidative degradation. The results of this test have been shown in table 1 . The pristine SPEEK-C membrane started to break after $60 \mathrm{~min}$ and got completely dissolved in $240 \mathrm{~min}$. However, the crosslinked membranes were more resistant towards oxidation and remained undissolved till $310 \mathrm{~min}$. The slower degradation of the crosslinked membranes is reasonable due to the lower water-absorbing capability and swelling ratio of the crosslinked membranes, 
Table 1. Water uptake, IEC, proton conductivity and oxidative stability properties of the membranes.

\begin{tabular}{|c|c|c|c|c|c|c|c|}
\hline \multirow[b]{2}{*}{ Samples } & \multirow{2}{*}{$\begin{array}{c}\text { Water } \\
\text { uptake }(\%)\end{array}$} & \multirow{2}{*}{$\begin{array}{c}\text { IEC } \\
\left(\text { meq }^{-1}\right)\end{array}$} & \multirow{2}{*}{$\begin{array}{l}\text { Proton conductivity } \\
\qquad\left(\mathrm{S} \mathrm{cm}^{-1}\right)\end{array}$} & \multicolumn{2}{|c|}{$\begin{array}{l}\text { Oxidative } \\
\text { stability (min) }\end{array}$} & \multirow{2}{*}{$\begin{array}{l}\text { Methanol permeability } \\
\qquad\left(\mathrm{cm}^{2} \mathrm{~s}^{-1}\right)\end{array}$} & \multirow{2}{*}{$\begin{array}{l}\text { Selectivity ratio } \\
\qquad\left(\mathrm{S} \mathrm{s} \mathrm{cm}^{-3}\right)\end{array}$} \\
\hline & & & & $T_{1}$ & $T_{2}$ & & \\
\hline SPEEK-C & 22 & 0.79 & 0.034 & 60 & 240 & $7.2 \times 10^{-5}$ & $4.7 \times 10^{2}$ \\
\hline SPEEK/PVA-5\% & 20.5 & 0.75 & 0.029 & 70 & 300 & $4.3 \times 10^{-5}$ & $6.0 \times 10^{2}$ \\
\hline SPEEK/PVA- $10 \%$ & 19 & 0.73 & 0.025 & 76 & 310 & $3.8 \times 10^{-5}$ & $6.5 \times 10^{2}$ \\
\hline SPEEK/PVA-15\% & 21 & 0.77 & 0.030 & 68 & 290 & $4.9 \times 10^{-5}$ & $6.1 \times 10^{2}$ \\
\hline
\end{tabular}

$T_{1}$ and $T_{2}$ refer to the time taken when the membrane samples start breaking and completely dissolve, respectively.

which results in lower diffusion of water molecules containing oxidizing radical species $\left(\mathrm{HO}^{\bullet}\right.$ and $\left.\mathrm{HOO}^{\bullet}\right)$. Moreover, the pendant carboxylic groups present in the SPEEK-C copolymer are sites prone to the oxidation, which is modified during the crosslinking reaction with PVA and hence results in increased oxidative stability. With increase in content of PVA, i.e., in case of SPEEK/PVA-15\% membrane, there is a decrease in oxidative stability. This may be due to the presence of unreacted PVA segment, which may undergo chain scission in Fenton's reagent and generate free radicals, which may act as oxidizing species and attack the terminal hydrogen atoms of the acid groups in the polymeric chains.

\subsection{Methanol permeability}

For better fuel cell performance, methanol permeability of the PEM should be low. It can be observed from table 1 that the methanol permeability is significantly reduced with the addition of PVA to the SPEEK-C random copolymer. This can be due to the formation of crosslinked network frame in the membrane structure, which blocks the transportation of methanol molecules. Additionally, the methanol permeability of the crosslinked SPEEK/PVA-15\% membrane was more than those of the other two crosslinked membranes. This increased methanol permeability of SPEEK/PVA-15\% membrane is due to the presence of more unreacted-OH groups of PVA, which causes degradation of the membranes and makes them more permeable.

\subsection{Selectivity ratio}

The PEM must have high proton conductivity and low methanol permeability. These two properties together can be expressed in terms of selectivity ratio, which is defined as the ratio of proton conductivity to the methanol permeability. Selectivity ratio is an important parameter to evaluate the performance of PEM. As the extent of crosslinking increases, selectivity ratio also increases. Higher the value of $\sigma / D_{\mathrm{K}}$, better the performance of the membrane. It is observed from table 1 that the selectivity ratio increases with increase in the PVA content in the crosslinked membranes.

\subsection{Thermal stability}

The thermal stabilities of the membranes also affect the fuel cell efficiency. The TG/DTG technique is considered to be the most favourable technique for determining thermal degradation of the polymer membranes. The TG and DTG curves of the membranes are shown in figure $6 \mathrm{a}$ and $\mathrm{b}$, respectively. All the sample membranes showed three-step weight loss patterns. The first weight loss step (below $150^{\circ} \mathrm{C}$ ) was due to the evaporation of absorbed water by sulphonic and carboxylic acid groups. The second step degradation of SPEEK-C copolymer in the range of $235-400^{\circ} \mathrm{C}$ was due to the decomposition of $-\mathrm{SO}_{3} \mathrm{H}$ and $-\mathrm{COOH}$ groups, but in the case of crosslinked SPEEK/PVA-XX membranes, the increase in the second step degradation temperature might be due to the formation of ester bond in the crosslinked membranes. However, the reason for the higher weight loss rate observed in case of crosslinked membranes can be attributed to the chain stripping elimination of water of the PVA segment in the temperature range $240-405^{\circ} \mathrm{C}$. The third step weight loss above $510^{\circ} \mathrm{C}$ was of the main polymer backbone of SPEEK-C, which further increased to $532^{\circ} \mathrm{C}$ in crosslinked membranes with the addition of PVA content.

The degradation temperatures at $5 \%$ weight loss $\left(T_{\mathrm{d}, 5 \%}\right)$ of SPEEK-C membrane $\left(156^{\circ} \mathrm{C}\right)$ was found to increase with crosslinking $\left(195^{\circ} \mathrm{C}\right)$ and are listed in table 2 . The incorporation of PVA in the matrix may increase the polymer matrix crystallinity and limit the movement of crosslinked polymer chains. Benefitting from the crosslinking structure, $T_{\mathrm{d}, 5 \%}$ of the crosslinked membranes is higher than that of the pristine SPEEK-C membrane, which clearly indicates the increased thermal stability of crosslinked membranes in the presence of PVA [21,22]. However, in off-stoichiometric mixture of SPEEK/PVA-15\%, the rapid chain-stripping elimination of water molecules causes its higher degradation rate. The char residue (\%) at $750^{\circ} \mathrm{C}$ of all the sample membranes has also been listed in table 2 .

The limiting oxygen index (LOI) value was calculated using Krevelen's equation [23] in order to confirm the flame retardancy of the synthesized membranes. The LOI represents the lowest environment's oxygen content for sustaining the flame. Generally, materials with LOI values higher than 


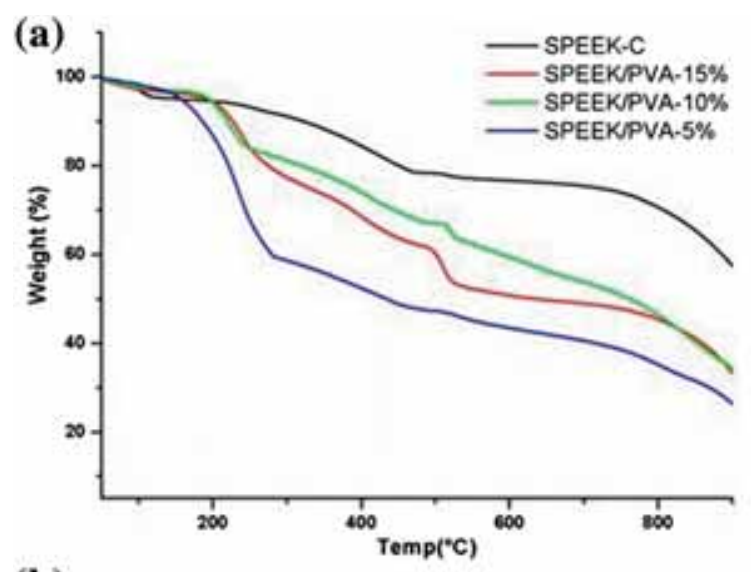

(b)

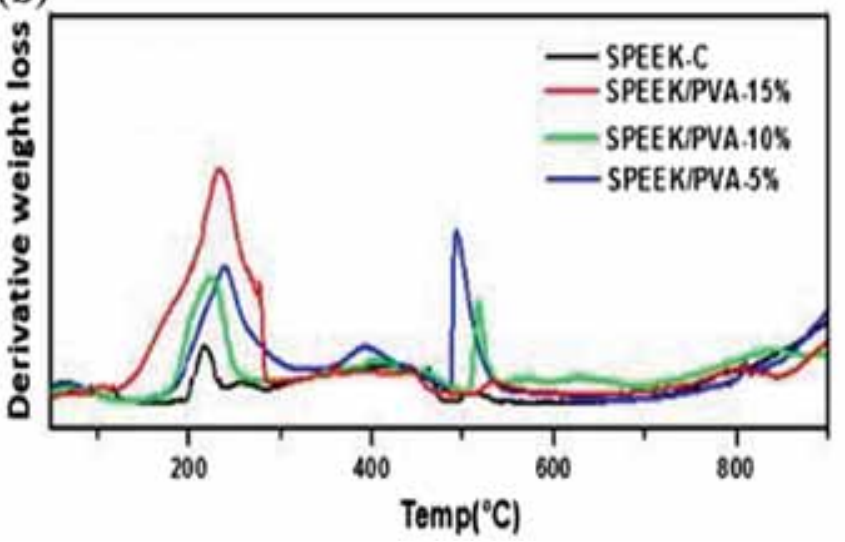

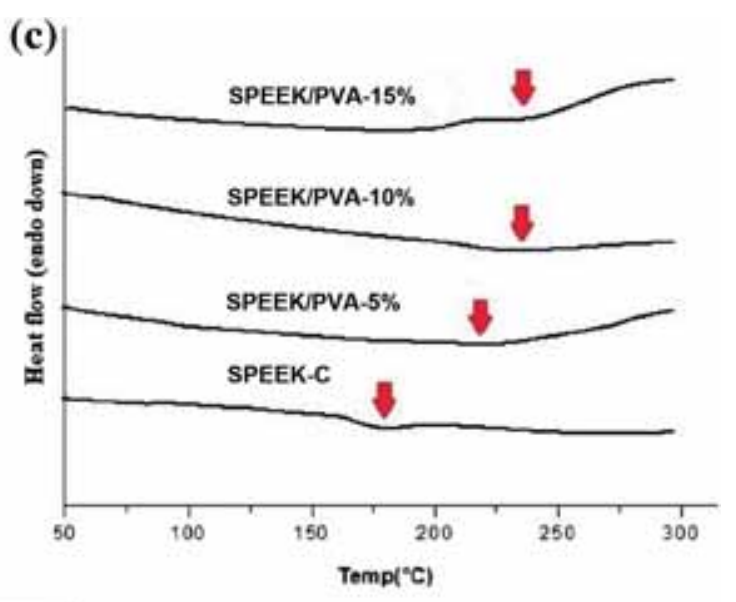

Figure 6. (a) TG, (b) DTG and (c) DSC curves of SPEEK-C and its crosslinked SPEEK/PVA membranes.

Table 2. Thermal behaviour description by TG/DTG and DSC curves.

\begin{tabular}{|c|c|c|c|c|c|c|c|}
\hline \multirow[b]{2}{*}{ Membranes } & \multirow[b]{2}{*}{$T_{\mathrm{d}, 5 \%}\left({ }^{\circ} \mathrm{C}\right)$} & \multicolumn{2}{|c|}{$\begin{array}{l}\text { Peaks of sulphonic and carboxylic } \\
\text { acids, temp. range }\left(200-450^{\circ} \mathrm{C}\right)\end{array}$} & \multirow{2}{*}{$\begin{array}{l}\text { Main peak of main chain, } \\
\text { temp. range }(500-600){ }^{\circ} \mathrm{C}\end{array}$} & \multirow[b]{2}{*}{$T_{\mathrm{g}}\left({ }^{\circ} \mathrm{C}\right)$} & \multirow{2}{*}{$\begin{array}{l}\text { Char residue } \\
(\%) \text { at } 750^{\circ} \mathrm{C}\end{array}$} & \multirow[b]{2}{*}{ LOI } \\
\hline & & Main peak & Secondary peak & & & & \\
\hline SPEEK-C & 156 & 235 & 400 & 510 & 176 & 75.47 & 47.68 \\
\hline SPEEK/PVA-5\% & 164 & 242 & 393 & 506 & 223 & 40.65 & 33.76 \\
\hline SPEEK/PVA-10\% & 195 & 240 & 405 & 530 & 235 & 53.85 & 39.04 \\
\hline SPEEK/PVA-15\% & 193 & 240 & 398 & 532 & 238 & 49.36 & 37.24 \\
\hline
\end{tabular}

$T_{\mathrm{d}, 5 \%}$ is the decomposition temperature at $5 \%$ weight loss.

26 show self-extinguishing behaviour and are considered to be highly flame retardant. As presented in table 2, all the membranes have LOI values greater than 33 , which indicate the good flame resistance behaviour of the synthesized membranes.

The DSC scans were used to elucidate the influence of PVA on the thermal transition behaviour of the membranes (figure 6c). The $T_{\mathrm{g}}$ of pristine SPEEK-C appeared at $176^{\circ} \mathrm{C}$ and the $T_{\mathrm{g}}$ for PVA (similar molecular weight) was reported to be at $88^{\circ} \mathrm{C}$ in the literature [24]. The crosslinked membranes exhibited significantly greater $T_{\mathrm{g}}$ with the addition of PVA, confirming the crosslinking of hydroxyl groups of PVA with carboxylic groups of the SPEEK-C. The crosslinked network structure restricts the mobility of polymer chain segments and a higher $T_{\mathrm{g}}$ is observed. The crosslinked membranes with 5-10\% PVA showed a single $T_{\mathrm{g}}$. However, off-stochiometric ratio with the increase in the content of PVA resulted in the presence of unreacted chains of PVA in the crosslinked network. Thus, in case of SPEEK/PVA-15\%, melting endotherm $\left(T_{\mathrm{m}}\right)$ at $208^{\circ} \mathrm{C}$ is observed, which is the same as that reported 

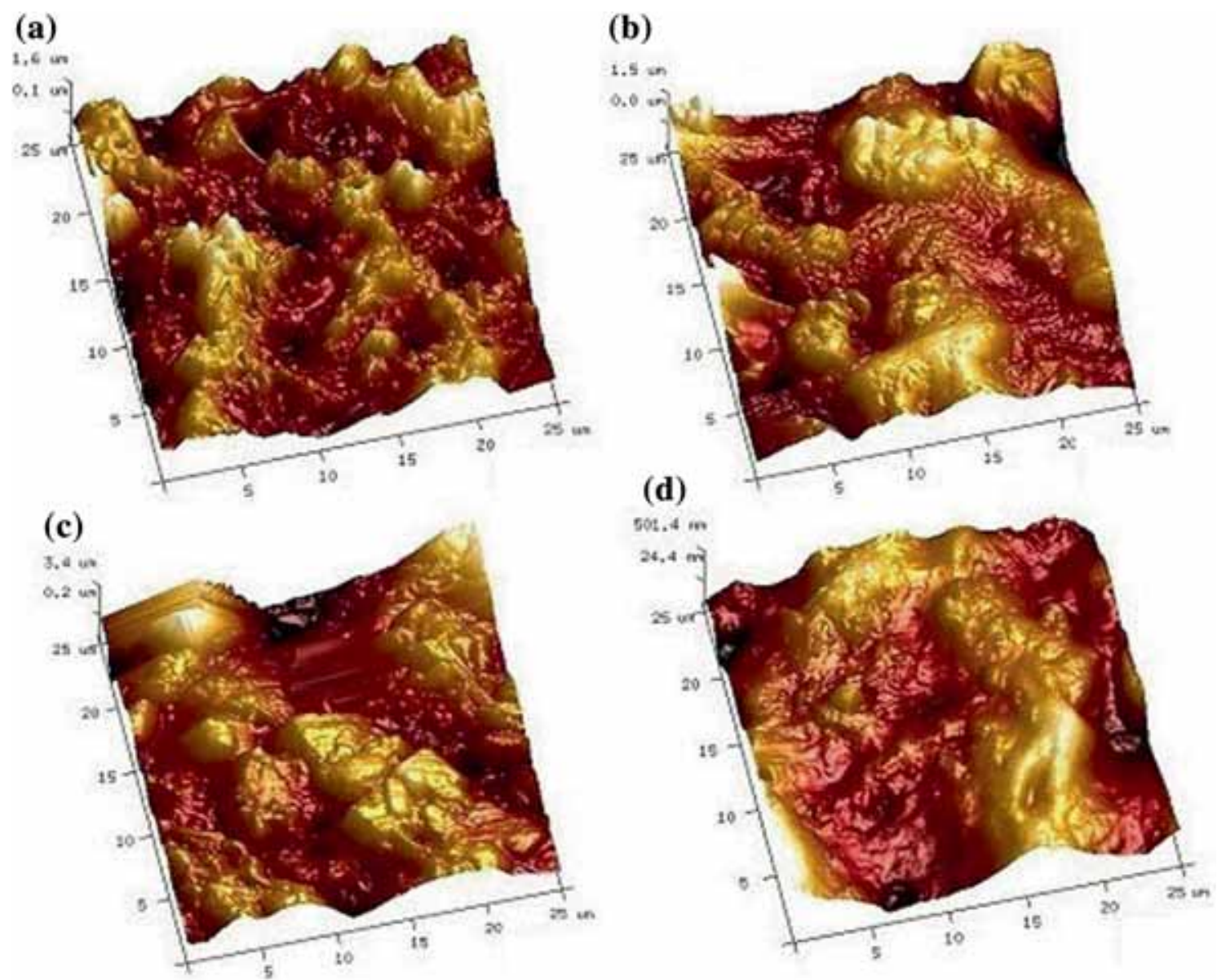

Figure 7. Three-dimensional tapping mode height images of (a) SPEEK-C, (b) SPEEK/PVA-5\%, (c) SPEEK/PVA$10 \%$ and (d) SPEEK/PVA-15\%.

by Guirguis and Manal [24]. The membranes though show a $T_{\mathrm{g}}$ at $238^{\circ} \mathrm{C}$, which is slightly higher than that of SPEEK/PVA$10 \%$, may be due to higher crosslink density of the network.

\subsection{Morphological characterization}

The microscopic morphologies of the pristine SPEEK-C and its crosslinked SPEEK/PVA-XX membranes were examined through AFM. Figure 7 shows the three-dimensional tapping mode height images of the pristine SPEEK-C (a), and its crosslinked counterpart membranes SPEEK/PVA-XX, with different PVA contents.

As noted in figure 7 , the light coloured region depicts the hydrophilic domains containing polar groups and the dark coloured region represents the hydrophobic domains. The ionic clusters in the hydrophilic domains are interconnected well to provide an effective proton-transport pathway. In SPEEK-C membrane (figure 7a), the presence of pendant carboxylic and sulphonic acid groups within the hydrophilic domains resulted in enhanced phase separation from the hydrophobic domains and therefore, appeared more distinct and well connected. However, after crosslinking, the interconnectivity of the hydrophilic channels and phase separation decreased as shown in figure $7 b-d$. This might be due to the reduction in the number of carboxylic acid groups, which were used to form the ester bonds with -OH group of PVA. The AFM morphology of crosslinked SPEEK/PVA$10 \%$ showed good hydrophilic domain connectivity as compared with that of SPEEK/PVA-5\%, giving rise to comparable good proton conductivity. From off-stoichiometric ratio of crosslinked SPEEK/PVA-15\%, the phase separation between hydrophobic and hydrophilic domains was not so homogenous due to the formation of highly crosslinked network structure. The aliphatic groups of PVA also increase the hydrophobic content in case of SPEEK/PVA-15\%. These observations suggest that the crosslinked SPEEK/PVA-10\% membrane provides an optimal morphology for the fuel cell application.

\section{Conclusions}

A new proton-conducting pristine SPEEK-C and crosslinked SPEEK/PVA membranes were successfully prepared using 
inexpensive DHBA bearing a pendant $-\mathrm{COOH}$ group. In addition, the degree of sulphonation of the sulphonated difluoro-monomer was also determined by the ${ }^{1} \mathrm{H}$-NMR spectroscopy technique. Compared with SPEEK-C membrane, the crosslinked membranes with PVA showed lower water uptake while maintaining the required proton conductivity in the range of $0.022-0.029 \mathrm{mS} \mathrm{cm}^{-1}$. The optimum membrane SPEEK/PVA-10\% is thermally more stable and has higher proton conductivity with comparable oxidative stability than the rest of other pristine/crosslinked membranes. The threedimensional AFM images of crosslinked SPEEK/PVA-XX membranes also showed the same result for the membrane with optimized PVA. Therefore, it can be concluded that the crosslinking reaction of SPEEK-C copolymer with PVA can serve as a suitable method to produce thermally stable PEMFC applications.

\section{References}

[1] Zhang L, Chae S R, Hendren Z, Park J S and Wiesner M R 2012 Chem. Eng. J. 20487

[2] Wang L, Wang D, Zhu G and Li J 2011 Eur. Polym. J. 471985

[3] Padmavathi R and Sangeetha D 2013 Ionics 191423

[4] Nagarale R K, Gohil G S and Shahi V K 2006 Adv. Colloid Interface Sci. 11997

[5] Peckham T J and Holdcroft S 2010 Adv. Mater. 224667

[6] Li H, Wu J, Zhao C, Zhang G, Zhang Y, Shao Ket al 2009 Int. J. Hydrogen Energy 348622
[7] Kim D J, Lee H J and Nam S Y 2014 Int. J. Hydrogen Energy 39 17524

[8] Zhao L, Huang Y D and Piao Y M 2008 E-polymer 8049

[9] Vega A M, Padilla Y and Bastarrachea M L 2015 Polym. Plast. Technol. Eng. $\mathbf{5 4} 711$

[10] Hickner M A, Ghassemi H, Kim Y S, Einsla B R and McGrath J E 2004 Chem. Rev. 1044587

[11] Changkhamchom S and Sirivat A 2013 Polym. Plast. Technol. Eng. 5270

[12] Zhang Y, Cui Z, Zhao C, Shao K and Li H 2009 J. Power Sources 191253

[13] Morfopoulou C, Andreopoulou A K and Kallitsis J K $2011 \mathrm{~J}$. Polym. Sci. Part A: Polym. Chem. 494325

[14] Wu T, Liu P, Shi M, Lu J, Ye G and Xu J 2011 Polym. Int. 60 1318

[15] Li D, Li Z, Hu F, Long S, Zhang G and Yang J 2014 Polym. Eng. Sci. 542013

[16] Lee K S, Jeong M H, Lee J P, Kim Y J and Lee J S 2010 Chem. Mater. 225500

[17] Zhu G K, Wang F G, Gao C and Liu Y 2012 Polym. Plast. Technol. Eng. $\mathbf{5 1} 386$

[18] Kiran V, Awasthi S and Gaur B 2015 Express Polym. Lett. 9 1053

[19] Kiran V and Gaur B 2015 Green Process. Synth. 4283

[20] Shahi V K 2007 Solid State Ion. 1773395

[21] Wang Y and Hsieh Y L 2010 J. Appl. Polym. Sci. 116 3249

[22] Xu J, Ni H, Wang S, Wang Z and Zhang H 2015 J. Membr. Sci. 492505

[23] Krevelen V D W 1975 Polymer 16615

[24] Guirguis O W and Manal T H M 2012 Nat. Sci. 457 